\title{
Composition of organic matter in peat soils of the northern trans-Urals depending on groundwater level
}

\author{
Anatoly Iglovikov ${ }^{1, *}$, and Alexander Motorin ${ }^{2}$ \\ ${ }^{1}$ Northern Trans-Ural State Agricultural University, Republic str., 7, Tuymen, 625003, Russia \\ ${ }^{2}$ Tyumen Research Centre, Siberian branch of the Russian Academy of Sciences, Malygina, 86, \\ Tuymen, 625026, Russia
}

\begin{abstract}
The paper presents the results of lysometric studies of the composition of organic matter of peat soils depending on the level of groundwater occurrence. It is established that the amount of bitumen in the arable layer $(0.2 \mathrm{~m})$ of medium-power peat soil at $0.5 \mathrm{~m}$ ground water level (UGV) is less by $1.65 \%$ than at the depth of $1.0 \mathrm{~m}$ and by $4.34 \%$ at $1.5 \mathrm{~m}$. There is no specific dependence on the UHW downstream of the soil profile. The increase of groundwater depth from 0.5 to $1.5 \mathrm{~m}$ reduces the amount of water-soluble and easily hydrolyzed substances in the arable layer at $100{ }^{\circ} \mathrm{C}$ from 5.68 to $4.48 \%$. At the groundwater level of $0.5 \mathrm{~m}$, the maximum presence $(34.25 \%)$ of substances hydrolysable by $2 \% \mathrm{HCl}$ was determined, which is $3.4-3.8 \%$ higher than at $1-1.5 \mathrm{~m}$. The maximum amount of humic acids in peat soil $(32.05 \%)$ is set at $0.5 \mathrm{~m}$ CKD. In the arable layer, the excess is $4.5 \%$ in comparison with one and a half meters of groundwater. The amount of fulvic acids practically does not depend on the groundwater table and is within the range of 17.7-17.9\%. With the same botanical composition of peat, the increase in the depth of groundwater occurrence from 0.5 to $1.5 \mathrm{~m}$ reduces the content of hard-tohydrolyze $80 \%$ of $\mathrm{H} 2 \mathrm{SO} 4$ substances in the arable layer from 2.82 to 2.31 $\%$. The number of compounds difficult to hydrolyze with acid is represented by $46-52 \%$ cellulose and does not depend on the level of groundwater. The presence of lignin in peat is several times higher than the cellulose content. There is a dependence of decrease in the lignin content at increase in depth of occurrence of ground waters from $0.5 \mathrm{~m}(6.63 \%)$ to $1.5 \mathrm{~m}(5.23 \%)$.
\end{abstract}

\section{Introduction}

Many agricultural properties of peat soils depend on the group composition of their organic matter. Resistance to biochemical and chemical degradation depends on the composition of the organic peat mass, which makes it possible to predict the erosion processes and the rate of mineralization of peat soils [1,2]. The organic mass of peat has a complex and heterogeneous chemical composition [3,4]. Chemical composition of peat-forming plants

\footnotetext{
*Corresponding author: an.iglovikov@mail.ru
} 
has a decisive influence on the composition of peat [5]. Even such methods of intensive anthropogenic influence as drainage, cultivation of various agricultural crops and mechanical treatment of peat soils cannot radically change the group composition of organic matter [6]. In natural conditions peat is formed at high moisture content, which restrains mineralization and humification and contributes to the conservation of biochemically unstable substances [7]. The group composition of organic matter in reclaimed peat soils is mainly determined by the geobotanical nature of peat and practically does not change much under the influence of various methods of agricultural use [8]. Under the conditions of the Northern Trans-Urals, the influence of the groundwater table on the organic matter composition of peat soils has not been studied. Therefore, research on this issue is not questionable.

The aim of the research is to study the impact of groundwater levels on the composition of organic matter in peat soils.

\section{Object and methods of the research}

The research was carried out in the Reshetnikovo experimental drainage area. Reshetnikovo experimental-reclamation system is located in Tyumen district in the central part of the Tarman bog massif, occupying the area of 125.8 thousand hectares on the second lake alluvial terrace of the river. Tours. There were laid 24 lysemeters, the area of one was 1.1 $\mathrm{m}^{2}$. Groundwater in leachates was maintained at the levels of $0.5 ; 1.0$ and $1.5 \mathrm{~m}$ during the year. Sedge-reed peat with a decomposition degree of 20-45\%. This article presents the results of studies with medium-decayed peat.

Average peat soils have low ash content (4.7-7.2\%), weakly acidic reaction of the environment (pHsol 5.6-6.2), relatively high hydrolytic acidity (21.2-40.8 mg-eq./100 g of soil), low saturation of bases (62-85\%). Fertilizers were applied in spring and after the first cut at the rate of $\mathrm{N}_{30} \mathrm{P}_{45} \mathrm{~K}_{45}$. The group composition of the organic matter of peat was studied by a modified method [9].

\section{Results of the research and its discussion}

As a result of long-term leasimetric researches we have established essential influence of a water regime of soil on group structure of organic substance of peat (tab. 1). Minimal bitumen content in the arable layer of soil is determined at 0.5 -meter level of groundwater occurrence. In this layer they are $1.65 \%$ less than at the groundwater level of $1.0 \mathrm{~m}$ and $4.34 \%$ less than at the ground water level of $1.5 \mathrm{~m}$. On the lysimeters with non-vegetation regulation of ground water the bitumen content is similar to the ones where the constant position of levels is equal to $1.0 \mathrm{~m}$. The maximum amount of bitumen $(10.85 \%)$ in the arable layer of soil is set at a deep $(1.5 \mathrm{~m})$ groundwater table. There is no specific pattern in the subsoil layers. Average content of bitumen in the whole studied soil profile differs insignificantly: $0.5 \mathrm{~m}-8.2 \% ; 1.0 \mathrm{~m}-8.4 \% ; 1.5 \mathrm{~m}-8.9 \% ; 2.0 \mathrm{~m}-8.1 \%$. In general, it is necessary to note the increased content of bitumen in the studied peat soil.

Water-soluble and easily hydrolysable substances at $100{ }^{\circ} \mathrm{C}$ account for a small proportion of all groundwater levels. On the average, their quantity in the soil profile varies in the range of $3.6-4.5 \%$. At the same time, there is no regularity. Only decrease of the considered group of substances in arable layer of soil is traced. For example, if at $0.5-$ meter level of groundwater occurrence in the arable layer they contain $5.62 \%, 1.0 \mathrm{~m}-5.12$ $\%, 1.5 \mathrm{~m}-4.48 \%$. At year-round regulation of groundwater levels, the content of watersoluble and easily hydrolysable substances at $100^{\circ} \mathrm{C}$ corresponds to their quantity under constant occurrence. 
Table 1: Group composition of organic matter of peat soil depending on the groundwater table, $\%$ for absolutely dry peat

\begin{tabular}{|c|c|c|c|c|c|c|c|c|c|c|c|}
\hline \multirow[b]{2}{*}{$\begin{array}{l}\Xi \\
\vdots \\
\vdots\end{array}$} & \multirow[b]{2}{*}{$\begin{array}{l}\text { E } \\
\text { हीं } \\
\text { ڤે̀ }\end{array}$} & \multirow[b]{2}{*}{$\stackrel{\mathscr{E}}{\stackrel{\mathscr{D}}{\Xi}}$} & \multicolumn{2}{|c|}{$\begin{array}{c}\text { Water-soluble } \\
\text { and easy to } \\
\text { hydrolyze at } \\
100^{\circ} \mathrm{C}\end{array}$} & \multicolumn{2}{|c|}{$\begin{array}{c}\text { Hydrolysable } 2 \% \\
\mathrm{HCl}\end{array}$} & \multirow[b]{2}{*}{ 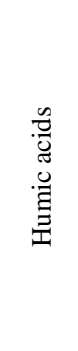 } & \multirow[b]{2}{*}{ 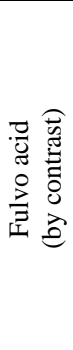 } & \multicolumn{2}{|c|}{$\begin{array}{c}\text { Difficult to } \\
\text { hydrolyze } 80 \\
\% \mathrm{H}_{2} \mathrm{SO}_{4}\end{array}$} & \multirow[b]{2}{*}{$\stackrel{\Xi \Xi}{\Xi}$} \\
\hline & & & $\begin{array}{l}\bar{\pi} \\
\text { ठัग } \\
0\end{array}$ & 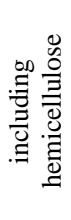 & च & 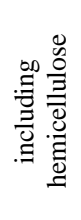 & & & $\begin{array}{l}\bar{\pi} \\
\text { ठัग } \\
0\end{array}$ & 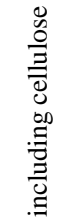 & \\
\hline \multirow[t]{4}{*}{0.5} & $0-0.2$ & 6.51 & 5.62 & left & 40.01 & 13.94 & 30.94 & 15.57 & 2.82 & 0.97 & 6.66 \\
\hline & $0.2-0.4$ & 8.68 & 5.29 & next & 36.88 & 13.65 & 29.30 & 18.04 & 2.66 & 0.99 & 6.88 \\
\hline & $0.4-0.6$ & 8.20 & 4.55 & next & 32.84 & 14.93 & 32.97 & 17.77 & 2.76 & 1.49 & 8.35 \\
\hline & $0.6-0.8$ & 9.30 & 2.69 & next & 27.28 & 14.83 & 34.98 & 17.31 & 2.61 & 1.61 & 4.63 \\
\hline \multirow[t]{4}{*}{1.0} & $0-0.2$ & 8.16 & 5.12 & next & 38.67 & 14.06 & 27.25 & 16.35 & 2.47 & 1.00 & 6.82 \\
\hline & $0.2-0.4$ & 6.59 & 4.47 & left & 33.08 & 14.04 & 31.75 & 17.60 & 2.59 & 1.14 & 5.53 \\
\hline & $0.4-0.6$ & 10.58 & 2.57 & left & 28.27 & 13.46 & 35.38 & 16.90 & 2.74 & 1.45 & 6.15 \\
\hline & $0.6-0.8$ & 6.94 & 2.64 & left & 26.16 & 14.59 & 31.29 & 18.55 & 2.70 & 1.90 & 4.78 \\
\hline \multirow[t]{4}{*}{1.5} & $0-0.2$ & 10.85 & 4.48 & left & 37.41 & 15.24 & 26.40 & 17.94 & 2.31 & 0.90 & 5.30 \\
\hline & $0.2-0.4$ & 6.65 & 5.46 & left & 30.45 & 15.43 & 30.63 & 18.06 & 2.62 & 1.10 & 5.22 \\
\hline & $0.4-0.6$ & 8.03 & 5.36 & left & 28.72 & 15.32 & 32.66 & 17.79 & 2.89 & 1.64 & 5.65 \\
\hline & $0.6-0.8$ & 10.14 & 2.84 & next & 26.53 & 15.29 & 32.12 & 17.74 & 2.61 & 1.15 & 4.76 \\
\hline $1-$ & $0-0.2$ & 8.54 & 5.19 & left & 35.36 & 14.97 & 28.07 & 18.28 & 2.34 & 1.01 & 6.11 \\
\hline \multirow[t]{3}{*}{2.0} & $0.2-0.4$ & 6.95 & 6.03 & left & 35.93 & 17.01 & 29.87 & 17.32 & 2.51 & 1.30 & 6.35 \\
\hline & $0.4-0.6$ & 7.47 & 4.58 & left & 33.0 & 17.86 & 28.33 & 17.46 & 2.89 & 1.34 & 6.43 \\
\hline & $0.6-0.8$ & 9.92 & 3.43 & left & 30.74 & 18.19 & 29.65 & 17.71 & 2.64 & 1.23 & 5.41 \\
\hline
\end{tabular}

The content of $\mathrm{HCl}$ substances in peat soils is rather high. It changes in soil profile in the range of 30.4-34.2\% at all groundwater levels. A certain dependence of the content of easily hydrolysable $2 \% \mathrm{HCl}$ substances on the level of groundwater occurrence is observed. The maximum (34.25\%) amount of groundwater $(0.5 \mathrm{~m})$ is recorded under close groundwater table. This is by 3.4-3.8\% more than at $1.0-1.5 \mathrm{~m}$ ground water level. At the same time, it should be noted that the largest difference in the content of lightly hydrolysable substances corresponds to the upper 0.4-meter soil layer. There are practically no differences in the soil profile downwards. At deep $(2.0 \mathrm{~m})$ winter groundwater occurrence the amount of light-hydrolysable substances is even slightly higher than at their all-year-round position of $1,0 \mathrm{~m}$, respectively 30,4 and $32,5 \%$. Hydrolysable $2 \% \mathrm{HCl}$ substances by $41.8-52.3 \%$ are represented by hemicellulose. Its minimum amount (14.0$14.3 \%$ ) is contained at ground water levels of $0,5-1,0 \mathrm{~m}$. The reduction of groundwater to $1.5 \mathrm{~m}$ increases the amount of hemicellulose to $15.3 \%$, i.e. by $7.0-9.2 \%$ compared to $0.5-$ $1.0 \mathrm{~m}$. The year-round regulation of the groundwater table provides the maximum content $(17.0 \%)$ of hemicellulose in peat soil.

It is known that macromolecules of humus substances have the highest resistance to biochemical decomposition, as their structural units are connected with a great variety of chemical bonds. Humic and fulvic acids account for almost half of the organic part of peat. Influence of level of ground waters occurrence on their maintenance is established. Thus, at 0.5 -meter level, the amount of humic acids in the average soil profile is $32.05 \%$, which is by $1.6 \%$ more than on 1.5 -meter lysimeters. The maximum reduction of humic acids $(4.5$ $\%$ ) occurs in the arable layer $(0.2 \mathrm{~m})$. Thus, it is confirmed that microbiological activity in peat soil increases with intensive drainage. The amount of fulvic acids practically does not depend on the groundwater table and is within the range of 17.7-17.9\%. Thus the ratio 
between the content of humic and fulvic acids fluctuates on a profile of soil in redistribution $(1: 0,53-0,61)$ at all levels of ground waters.

In medium-power peat soils the content of hard-to-hydrolyze $80 \%$ of $\mathrm{H} 2 \mathrm{SO} 4$ compounds does not exceed $2.8 \%$ and does not reveal a certain connection with other components of peat. At the same botanical composition with the increase in the depth of groundwater occurrence the content of hard-to-hydrolyze substances decreases. For example, at 0.5 -metre ground water level, their quantity is $2.7 \%$, and 1.5 -metre $-2.6 \%$. The most significant reduction $(0.5 \%)$ occurs in the arable layer. There is no correlation with the degree of decomposition. Compounds that are difficult to hydrolyze with acid are largely represented by cellulose. In the studied peat content is $46-52 \%$ of the total amount of hard-to-hydroldizable peat and practically does not depend on the groundwater level.

The residue, which does not undergo hydrolysis with $80 \%$ sulphuric acid, is considered lignin. The amount of lignin in peat was several times higher than the cellulose content. Fluctuations in the lignin content at $0.5 \mathrm{~m}$ UHV are within the range of $4.63-8.35 \%$ (average $6.63 \%$ ), $1.0 \mathrm{~m}-5.53-6.82(5.82 \%), 1.5 \mathrm{~m}-4.76-5.65$ (5.23\%), $2.0 \mathrm{~m}-5.41-$ $6.11(6.07 \%)$. The dependence of decrease in lignin content at increase in depth of groundwater occurrence is observed. The variant, where non-vegetation regulation of ground waters was carried out, falls out of this dependence. Compared to the constant groundwater table, the lignin content increased by $0.25 \%$ ( $4.3 \%$ growth).

\section{Conclusion}

1. In arable layer $(0.2 \mathrm{~m})$ of peat soil the content of bitumen at 0.5 -meter UHV $(6.51 \%)$ is less on $1.65 \%$, than at depth of $1.0 \mathrm{~m}$ and on $4.34 \%$ at one and a half meter lysimeters. There is no certain dependence on the ground water level down the soil profile.

2. The increase in groundwater depth from 0.5 to $1.5 \mathrm{~m}$ reduces the amount of watersoluble and easily hydrolysable substances in the arable layer at $100{ }^{\circ} \mathrm{C}$ from 5.68 to 4.48 $\%$.

At the groundwater level of $0.5 \mathrm{~m}$ the maximum amount $(34.25 \%)$ of hydrolysable substances of $2 \% \mathrm{HCl}$ is determined. This is by $3.4-3.8 \%$ more than at $1-1.5 \mathrm{~m}$ ground water level.

3. The maximum amount of humic acids in peat soil (32.05\%) is established at $0.5 \mathrm{~m}$ UHV. In the arable layer the excess is $4.5 \%$ in comparison with one and a half meters of ground water level.

The amount of fulvic acids practically does not depend on the groundwater table and is within the range of $17.7-17.9 \%$.

4. With the same botanical composition of peat, the increase in the depth of groundwater occurrence from 0.5 to $1.5 \mathrm{~m}$ reduces the content of hard-to-hydrolyze $80 \%$ of $\mathrm{H}_{2} \mathrm{SO}_{4}$ substances in the arable layer from 2.82 to $2.31 \%$.

The number of compounds difficult to hydrolyze with acid is represented by $46-52 \%$ cellulose and does not depend on the level of groundwater.

5. There is a dependence of reduction of lignin content at increase in depth of groundwater occurrence from $0.5 \mathrm{~m}(6.63 \%)$ to $1.5 \mathrm{~m}(5.23 \%)$. The presence of lignin in peat is several times higher than the cellulose content.

\section{References}

1. A.S. Motorin, A.V. Iglovikov Izvestiya Orenburg State Agrarian University 6(74), $12-$ 15. (2018)

2. L.I. Inisheva, T.V. Dementieva Soil science 2, 196-203. (2000) 
3. I.V. Grekhova. Agrarian Bulletin of the Urals 6, 14-16. (2012)

4. V.S. Arkhipov, S.G. Maslov. Chemistry of vegetable raw materials 4, 9-16. (1998)

5. A.S. Motorin, A.V. Iglovikov. IOP Conference Series: Earth and Environmental Science electronic edition. 042016. (2018)

6. A.V. Iglovikov, A.S. Motorin, A.V. Bukin IOP Conference Series: Earth and Environmental Science electronic edition. 082026, (2018)

7. L.N. Inisheva. Chemistry of vegetable raw materials 4, 17-22. (1998)

8. N.N. Bambalov, V.A. Rakovich. The role of bogs in the biosphere. Minsk, Bel. Nauka, (2005)

9. N.N. Bambalov, T.Ya. Belenkaya. Melioration and problems of the organic matter. Minsk, 92-102. (1994) 